\title{
CMAJ Humanities adopts a second critical lens
}

\author{
Dorian Deshauer MD, Barbara Sibbald BJ
}

B iotechnology tends to shift what we take for granted as natural or normal. ${ }^{1}$ In the process, the boundaries between biology, economics and politics become blurred. Take, for example, the sequencing of the human genome and its entanglement with laboratory, commercial and regulatory conflicts. ${ }^{2}$ New zones of social inclusion and exclusion emerge, not only here in the affluent West but on a global scale.

Molecular biology aspires to universal truths, yet attempts at mapping biology onto culture have led to abuses of science. The definition of normality is never a disinterested statistical construct, but rather a reflection of those in whose image it is made.

A new generation of social analysts is working to understand medicine's role in society from the perspective of emerging technologies, especially high-tech interventions, and their links to global economic and political forces.

Typically, scholarship in this area is published in nonmedical academic journals, which ironically keeps the people who study medicine's role in society and those who practise medicine from engaging one another. If our shared goal is to develop more relevant, inclusive forms of health care, the current arrangement is at the very least misguided and may propagate unproductive silos. Would it not make more sense for social critics to speak directly to doctors, and vice versa?

Starting with this issue, $C M A J$ is refocusing its Humanities section on the economic, policy and personal implications of attempts to control biology. In the spirit of open communication across the disciplines, we encourage contributors not only from the field of medicine but also from sociology, anthropology, science studies, disability studies, ethics and history to share their work in brief, peer-reviewed essays under the heading "Medicine and Society" (www.cmaj.ca/site/authors/ preparing.xhtml\#_Humanities). To ensure fairness and quality, we have assembled an interdisciplinary advisory panel to oversee submissions and to help in the selection of reviewers (www.cmaj .ca/site/misc/cmaj-medicine-in-society-advisory-panel.xhtml).

Just as emerging relationships between technology, economics and policy enable new ways of living, they raise moral and ethical questions. In this issue of CMAJ, the Humanities section features a case in point. Sergio Sismondo uses an extreme example to remind us that scientific facts cannot be considered apart from the interests of the researchers who define them. He does this by revisiting the uncomfortable problem of key opinion leaders and their industrial handlers.
Beware of simplistic conflict-of-interest statements designed to appease by meeting regulators' minimum standards.

Of course, the methods of institutional analysis tend to exclude an important way of knowing, the kind that comes from a deep inner experience. Personal accounts of caring for others, living with an illness or living under the term "disabled" remain powerful ways of connecting patients, their doctors and society. Such accounts will continue to serve as one of our lenses on contemporary medicine. This is "narrative medicine," a phrase coined by Dr. Rita Charon, who wrote that "a scientifically competent medicine alone cannot help a patient grapple with the loss of health or find meaning in suffering. Along with scientific ability, physicians need the ability to listen to the narratives of the patient, grasp and honor their meanings, and be moved to act on the patient's behalf." 3

For medical professionals, narratives provide insight into illness, suffering, death and the practice of medicine and help to develop and nurture the skills of observation, analysis, empathy and self-reflection. They also broaden a doctor's cultural competence and encourage the linking of both cognitive and affective approaches to the physician's task, which is essential for humane medical care.

$C M A J$ Humanities will therefore have two critical lenses. One will look past the professional boundaries of medicine to the political and economic forces shaping knowledge and practice. The other will focus on the lived experiences of doctors and patients. Our purpose is to explore how the relationship between these perspectives is constantly recalibrating, changing the meaning of health, sickness and the role of medicine in society.

\section{References}

1. Clarke A, Mamo L, Fosket JR, et al.; editors. Biomedicalization: technoscience, health, and illness in the US. Durham and London: Duke University Press; 2010.

2. Mirowski P. Science-Mart: privatizing American science. Cambridge (MA): Harvard University Press; 2011:290-4.

3. Charon R. Narrative medicine: a model for empathy, reflection, profession, and trust. JAMA 2001;286:1897-902.

Competing interests: See www.cmaj.ca/site/misc/cmaj_staff.xhtml

Affiliations: News and Humanities Editor (Sibbald) and Associate Editor (Deshauer), CMAJ

Correspondence to: $C M A J$ editor, pubs@cmaj.ca

CMAJ 2015. DOI:10.1503/cmaj.150517 